\title{
Randomized trial of preladenant, given as monotherapy, in patients with early Parkinson disease
}

Fabrizio Stocchi, MD,

$\mathrm{PhD}$

Olivier Rascol, MD

Robert A. Hauser, MD, MBA

Susan Huyck, DrPH

Anjela Tzontcheva, PhD

Rachel Capece, BS

Tony W. Ho, MD

Peter Sklar, MD, MPH

Christopher Lines, PhD

David Michelson, MD

David J. Hewitt, MD

On behalf of the

Preladenant Early

Parkinson Disease

Study Group

Correspondence to

Dr. Stocchi:

fabrizio.stocchi@fastwebnet.it

\section{ABSTRACT}

Objective: To evaluate the adenosine 2 a receptor antagonist preladenant as a nondopaminergic drug for the treatment of Parkinson disease (PD) when given as monotherapy.

Methods: This was a randomized, 26-week, placebo- and active-controlled, parallel-group, multicenter, double-blind trial conducted in adults diagnosed with PD for $<5$ years who were not yet receiving L-dopa or dopamine agonists. Patients with a Unified Parkinson's Disease Rating Scale (UPDRS) part 3 (motor function) score $\geq 10$ and Hoehn \& Yahr score $\leq 3$ were randomized 1:1:1:1:1 to preladenant 2, 5 , or $10 \mathrm{mg}$ twice daily, rasagiline $1 \mathrm{mg}$ (active-control) once daily, or placebo. The primary endpoint was the change from baseline at week 26 in the sum of UPDRS parts 2 (activities of daily living) and 3 scores (UPDRS $2+3$ ).

Results: The number of patients treated was 1,007 . Neither preladenant nor rasagiline was superior to placebo after 26 weeks. The differences vs placebo (95\% confidence interval) in UP$\mathrm{DRS}_{2+3}$ scores (with a negative difference indicating improvement vs placebo) were preladenant $2 \mathrm{mg}=2.60(0.86,4.30)$, preladenant $5 \mathrm{mg}=1.30(-0.41,2.94)$, preladenant $10 \mathrm{mg}=0.40(-1.29,2.11)$, and rasagiline $1 \mathrm{mg}=0.30(-1.35,2.03)$. Post hoc analyses did not identify a single causal factor that could explain the finding of a failed trial. Preladenant was generally well-tolerated with few patients discontinuing due to adverse events (preladenant 7\%, rasagiline 3\%, placebo 4\%).

Conclusions: No evidence supporting the efficacy of preladenant as monotherapy was observed in this phase 3 trial. The lack of efficacy of the active control rasagiline makes it difficult to interpret the results.

Clinical trial registration: Clinicaltrials.gov: NCT01155479.

Classification of evidence: This study provides Class I evidence that for patients with early PD, preladenant is not effective as monotherapy at the doses studied $\left(2,5,10\right.$ mg). Neurology ${ }^{\circledR}$ 2017;88:2198-2206

\section{GLOSSARY}

AST = aspartate aminotransferase; $\mathbf{C l}=$ confidence interval; DSM-IV = Diagnostic and Statistical Manual of Mental Disorders, 4th edition; PD = Parkinson disease; OR = odds ratio; ULN = upper limit of normal; UPDRS = Unified Parkinson's Disease Rating Scale.

The adenosine $2 \mathrm{a}\left(\mathrm{A}_{2 \mathrm{~A}}\right)$ receptor is a nondopaminergic target for the treatment of Parkinson disease (PD). ${ }^{1-3}$ Selective $A_{2 A}$ receptor antagonists such as istradefylline and tozadenant have been assessed for efficacy as adjunct treatment to levodopa in patients with moderate to severe PD with mixed findings. ${ }^{4-9}$ To date, only istradefylline is approved for treating PD, and only in Japan. Preladenant is an investigational potent selective $\mathrm{A}_{2 \mathrm{~A}}$ receptor antagonist. ${ }^{10,11}$ In a phase $2 \mathrm{~b}$ trial evaluating preladenant as an adjunct to L-dopa in patients with fluctuating PD, the drug provided a significant reduction in off time compared to placebo. ${ }^{12}$ These findings were not confirmed in 2 subsequent phase 3 trials, but the failure of an active

\footnotetext{
From the Institute of Neurology (F.S.), IRCCS San Raffaele, Rome, Italy; Departments of Clinical Pharmacology and Neurosciences (O.R.), Clinical Investigation Center CIC1436, NS-Park Clinical Research Network, NeuroToul Centre of Excellence in Neurodegeneration, INSERM, Toulouse University Hospital and Toulouse University, France; Parkinson's Disease and Movement Disorders Center (R.A.H.), USF Health-Byrd Institute, Tampa, FL; and Merck \& Co., Inc. (S.H., A.T., R.C., T.W.H., P.S., C.L., D.M., D.J.H.), Kenilworth, NJ. Coinvestigators are listed at Neurology.org.

Go to Neurology.org for full disclosures. Funding information and disclosures deemed relevant by the authors, if any, are provided at the end of the article.
} 
control, rasagiline, that was included in one of the trials makes it difficult to interpret the results. ${ }^{13}$

Selective $A_{2 A}$ receptor antagonists administered by themselves have been shown to improve motor disability in rodent and nonhuman primate experimental models of PD, suggesting that they could be effective when used as monotherapy in patients with early PD. ${ }^{10,11,14,15}$ The only adequately sized monotherapy trial of a selective $\mathrm{A}_{2 \mathrm{~A}}$ receptor antagonist to date did not find a significant effect of istradefylline over 12 weeks on motor function compared with placebo, although there was a numerical improvement. ${ }^{16}$ Here we report the results of a trial of preladenant given as monotherapy in patients with early PD. Rasagiline, an MAO-B inhibitor with established efficacy as monotherapy, was used as an active control. ${ }^{17,18}$ The primary objective of the trial was to demonstrate efficacy of preladenant over placebo.

METHODS Participants. Participants were enrolled at 153 sites in the Americas, Europe, South Africa, India, and Turkey from October 2010 to August 2013. Eligible participants were adults diagnosed with idiopathic PD according to the UK PD Society Brain Bank criteria, ${ }^{19}$ and confirmed by the presence of at least 2 of the cardinal signs (bradykinesia, muscular rigidity, and resting tremor). If resting tremor was not present, rigidity or bradykinesia had to be asymmetric; furthermore, a diagnosis based solely on bradykinesia and postural instability was considered insufficient. Participants had disease severity no greater than Hoehn \& Yahr stage 3 and Unified Parkinson's Disease Rating Scale (UPDRS) part 3 (motor function) score of $\geq 10$ at screening. ${ }^{20}$ Key exclusion criteria included drug-induced or atypical parkinsonism, prior surgery for $\mathrm{PD}$, cognitive impairment (Montreal Cognitive Assessment score <22), ${ }^{21}$ untreated major depressive disorder (DSM-IV criteria ${ }^{22}$ or a Beck Depression Inventory II score $\geq 19$ ), ${ }^{23}$ impulse control disorders, hallucinations, and other significant conditions that could interfere with assessments or participation (e.g., psychotic disorder, stroke, and head injury). Eligible participants had not taken L-dopa or dopamine agonists for 30 days or more. Participants receiving anticholinergics or amantadine at a stable dosage for at least the 5 weeks immediately prior to screening were eligible. Those who had taken MAO inhibitors, including rasagiline, within 30 days prior to randomization were not eligible.

Design and study treatment. This was a randomized, doubleblind, parallel-group, multicenter trial, conducted in 2 parts of 26 weeks each. In part 1, participants were randomized 1:1:1:1:1 to preladenant 2,5 , or $10 \mathrm{mg}$ twice daily, rasagiline $1 \mathrm{mg}$ (activecontrol) once daily, or placebo. The primary research question was whether preladenant compared with placebo improves activities of daily living plus motor function in patients with early PD. In part 2, participants treated with placebo in part 1 were switched to preladenant $5 \mathrm{mg}$ twice daily while the others remained on their part 1 treatment; the placebo/preladenant group was intended as a delayed start group for exploratory efficacy comparison to the $5 \mathrm{mg}$ preladenant/preladenant group to assess potential disease-modifying effects if efficacy was demonstrated in part 1.

During the trial, initiation of PD treatments beyond those used at baseline was strongly discouraged. However, if a participant developed an urgent need during the trial, PD treatments (amantadine, anticholinergics, dopaminergic therapy) could be prescribed.

Participants were assigned to treatment using a computergenerated randomized allocation schedule prepared by Merck and implemented through an interactive voice response system. Randomization was stratified by history of L-dopa/dopamine agonist use (none vs $<30$ days). Investigators, site staff, participants, and monitoring staff remained blinded to treatment allocation throughout the trials.

Standard protocol approvals, registrations, and patient consents. The trial was conducted in accordance with principles of Good Clinical Practice, and was approved by appropriate institutional review boards and regulatory agencies. All participants provided written informed consent. This trial is registered in clinicaltrials.gov NCT01155479, Merck Protocol MK-3814-024.

Assessments. Participants were examined at screening, baseline (day 1 prior to randomization), and 2, 4, 8, 16, and 26 weeks after randomization. At each examination, the investigator rated the participants with the UPDRS ${ }^{20}$ including mental function (part 1), activities of daily living (part 2), motor function (part 3 ), and complications of therapy (part 4). The person administering the UPDRS was experienced in its use and underwent further training and testing for the trial. As far as possible, the UPDRS was administered by the same experienced qualified rater for a given participant across clinic visits.

Safety was assessed by review of adverse events (AEs), laboratory values, vital signs, and ECGs in all participants who took treatment. Hepatic function was a particular focus since elevated liver function tests (alanine aminotransferase [ALT] and aspartate aminotransferase $[\mathrm{AST}]$ ) were observed in previous preladenant studies at higher doses than evaluated here.

Statistical analysis. The primary outcome was change from baseline in the sum of UPDRS parts 2 and 3 scores $\left(\mathrm{UPDRS}_{2+3}\right.$ ). This endpoint has been used in several de novo trials with dopamine agonists. ${ }^{24,25}$ The primary hypothesis was that at least preladenant $10 \mathrm{mg}$ is superior to placebo as measured by the change from baseline to week 26 in $\mathrm{UPDRS}_{2+3}$. The primary efficacy endpoint was analyzed using a constrained longitudinal data analysis approach with treatment, time, treatment-by-time interaction, strata, and participant effects in the model. The least squares mean response and pairwise differences between preladenant doses and placebo, along with $95 \%$ confidence intervals (CI), are reported. A comparison of rasagiline vs placebo was performed using the same model. The efficacy population (full analysis set) consisted of all randomized participants with baseline data and postrandomization endpoint data subsequent to $\geq 1$ dose of study medication.

It was planned that approximately 1,000 participants (200 per treatment arm) would be randomized. Results from the TEMPO trial showed that rasagiline improved $\mathrm{UPDRS}_{2+3}$ scores by approximately 3.5 points over placebo with a pooled standard deviation of 7.2 points. ${ }^{26}$ Based on a literature review of recent clinical trials studying the same primary endpoint, the estimated SD was expected to be 9 points. Using a SD of 9 points and a 2 -sided $\alpha=0.05,200$ participants in each arm provided at least 
$91 \%$ power to detect a clinically relevant difference of 3 points in $\mathrm{UPDRS}_{2+3}$ scores between preladenant and placebo.

Key secondary endpoints were the proportion of responders (proportion of participants with at least a $20 \%$ improvement in $\mathrm{UPDRS}_{2+3}$ from baseline at week 26) and change from baseline to week 26 in the UPDRS part $2\left(\mathrm{UPDRS}_{2}\right)$ score. Responder rates for each treatment arm are presented along with odds ratios (ORs) and 95\% CIs for the ORs comparing preladenant dose groups with placebo. The change from baseline in the UPDRS 2 score was evaluated using the primary endpoint model.

Multiplicity for the preladenant vs placebo comparisons was controlled using an ordered testing procedure (see e-Methods at Neurology.org).

Post hoc investigations. Once efficacy results of part 1 of the trial were known, a number of post hoc investigations were undertaken. The potential effect of caffeine consumption at baseline was evaluated by adding a caffeine term to the primary analysis model. Caffeine is a nonspecific adenosine receptor antagonist that has been speculated to have a protective effect in PD. ${ }^{14,27}$ Results were also analyzed according to geographic area, as this was found to have an influence on efficacy in a preladenant adjunct trial. ${ }^{13}$

Classification of evidence. This study provides Class I evidence that for patients with early PD, preladenant is not effective as monotherapy at the doses studied $(2,5,10 \mathrm{mg})$.

RESULTS Participants. Of 1,022 participants randomized, 1,007 were treated and 868 (86\% of those treated) completed part 1 with discontinuations being similar across treatment groups (figure 1). Part 2 of the trial was terminated early after the results of part 1 were available and 2 phase 3 adjunctive treatment trials $^{13}$ failed to demonstrate superiority of preladenant over placebo (figure e-1).

Baseline characteristics were similar among treatment groups (table 1). Approximately a third of participants in each treatment group took concomitant PD medications (table 1). Of the PD medications used, $53 \%$ were amantadine, $27 \%$ were anticholinergics, $8 \%$ were dopamine agonists, $6 \%$ were L-dopa, and $7 \%$ were other types.

Efficacy. In part 1, neither preladenant nor rasagiline was superior to placebo in improving $\mathrm{UPDRS}_{2+3}$ change from baseline score at week 26 (table 2). Although there was a dose response for preladenant at all timepoints on the primary endpoint, and the efficacy of preladenant $10 \mathrm{mg}$ appeared similar to rasagiline, the placebo arm had the highest improvement and therefore treatment differences vs placebo were not significant (figure 2). The secondary endpoints of the proportion of responders and UPDRS 2 change from baseline score at week 26 also showed no significant differences between preladenant or rasagiline vs placebo (table 2). Due to the failure of preladenant in part 1 and the early termination of part 2 of the trial, no efficacy analyses were performed for part 2 .

Safety. A summary of AEs during part 1 is shown in table e- 1 . AEs were reported by around 54\%-59\% of participants treated with preladenant and $52 \%$ of participants treated with either rasagiline or

\begin{tabular}{|c|c|c|c|c|}
\hline & & $\begin{array}{l}\text { Randomized } \\
(\mathrm{N}=1,022)\end{array}$ & & \\
\hline $\begin{array}{l}\text { Treated } \\
(n=200)\end{array}$ & $\begin{array}{l}\text { Treated } \\
(n=202)\end{array}$ & $\begin{array}{l}\text { Treated } \\
(n=204)\end{array}$ & $\begin{array}{l}\text { Treated } \\
(n=198)\end{array}$ & $\begin{array}{l}\text { Treated } \\
(n=203)\end{array}$ \\
\hline $\begin{array}{l}\text { Discontinued }(n=34) \text { : } \\
\text { - Adverse event }(13) \\
\text { - Treatment failure (3) } \\
\text { - Withdrew (11) } \\
\text { - Protocol violation (5) } \\
\text { - Administrative (2) }\end{array}$ & $\begin{array}{l}\text { Discontinued }(\mathrm{n}=25) \text { : } \\
\text { - Adverse event (8) } \\
\text { - Withdrew (13) } \\
\text { - Protocol violation (2) } \\
\text { - Administrative (2) }\end{array}$ & $\begin{array}{l}\text { Discontinued ( } n=37) \text { : } \\
\text { - Adverse event (18) } \\
\text { - Treatment failure (3) } \\
\text { - Lost to follow-up (1) } \\
\text { - Withdrew (8) } \\
\text { - Protocol violation (5) } \\
\text { - Administrative (2) }\end{array}$ & $\begin{array}{l}\text { Discontinued }(n=21) \text { : } \\
\text { - Adverse event }(7) \\
\text { - Treatment failure (1) } \\
\text { - Lost to follow-up (1) } \\
\text { - Withdrew (8) } \\
\text { - Protocol violation (4) }\end{array}$ & $\begin{array}{l}\text { Discontinued }(n=22) \text { : } \\
\text { - Adverse event }(6) \\
\text { - Treatment failure (2) } \\
\text { - Withdrew (9) } \\
\text { - Protocol violation (5) }\end{array}$ \\
\hline $\begin{array}{l}\text { Completed } \\
(n=166)\end{array}$ & $\begin{array}{l}\text { Completed } \\
(n=177)\end{array}$ & $\begin{array}{l}\text { Completed } \\
(n=167)\end{array}$ & $\begin{array}{l}\text { Completed } \\
(n=177)\end{array}$ & $\begin{array}{c}\text { Completed } \\
(n=181)\end{array}$ \\
\hline $\begin{array}{l}\text { Analyzed: } \\
\text { - Efficacy }\left(n=195^{\star}\right) \\
\text { - Safety }(n=200)\end{array}$ & $\begin{array}{l}\text { Analyzed: } \\
\text { - Efficacy }(n=202) \\
\text { - Safety }(n=202)\end{array}$ & $\begin{array}{l}\text { Analyzed: } \\
\text { - Efficacy }\left(n=200^{*}\right) \\
\text { - Safety }(n=204)\end{array}$ & $\begin{array}{l}\text { Analyzed: } \\
\text { - Efficacy }\left(n=195^{\star}\right) \\
\text { - Safety }(n=198)\end{array}$ & $\begin{array}{l}\text { Analyzed: } \\
\text { - Efficacy }\left(n=195^{\star}\right) \\
\text { - Safety }(n=203)\end{array}$ \\
\hline
\end{tabular}

*Fewer than the number treated due to missing postbaseline data. 
Table 1 Baseline characteristics of randomized participants

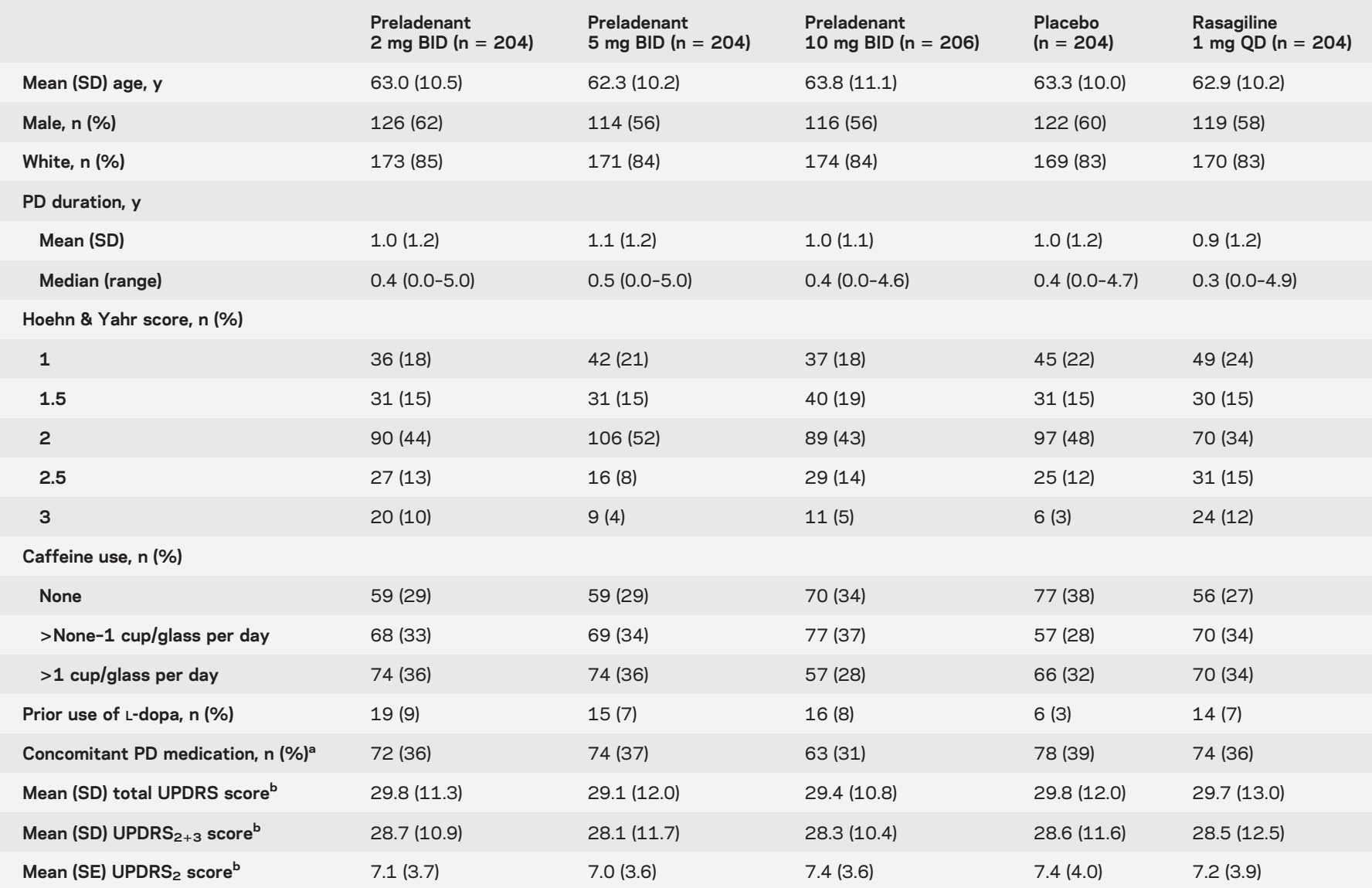

Abbreviations: PD = Parkinson disease; UPDRS = Unified Parkinson's Disease Rating Scale.

${ }^{\text {a } B a s e d ~ o n ~ t r e a t e d ~ p a r t i c i p a n t s ; ~ f i g u r e ~} 1$ for sample sizes.

${ }^{\mathrm{b}}$ Based on full analysis set; table 2 for sample sizes.

placebo. Relatively few participants discontinued due to AEs (preladenant $4 \%-10 \%$, rasagiline $3 \%$, placebo 4\%). The most common $\mathrm{AE}$ with preladenant was headache ( $4 \%-7 \%$ vs $3 \%$ for placebo) and the most common $\mathrm{AE}$ with rasagiline was dizziness ( $5 \%$ vs $5 \%$ for placebo). One death was reported during part 1; a participant in the preladenant 10 mg group had a hemorrhagic vascular stroke, which was considered by the investigator to be unlikely to be related to study drug.

A summary of AEs during part 2 is shown in table e-2. During part 2, around $68 \%$ of participants reported AEs across treatment arms, higher than in part 1 of the study. There were no striking differences between treatment groups. The most common AE with preladenant was headache $(6 \%-10 \%)$ and the most common $\mathrm{AE}$ with rasagiline was dizziness (9\%). One death was reported during part 2; a participant in the preladenant $10 \mathrm{mg}$ group died from a sudden cardiac event, which was considered by the investigator to be unlikely to be related to study drug.

In part 1 , ALT increases $>3 \times$ the upper limit of normal (ULN) were preladenant $2 \mathrm{mg}=1.0 \%(2 /$ $194), 5 \mathrm{mg}=1.5 \%(3 / 198), 10 \mathrm{mg}=4.6 \%(9 / 196)$, placebo $=0 \%(0 / 193)$, and rasagiline $=1.5 \%(3 /$ 195). In part 2 , rates were more similar in the preladenant and rasagiline arms: preladenant $2 \mathrm{mg}=$ $1.2 \%(2 / 165), 5 \mathrm{mg}=1.2 \%(2 / 173), 10 \mathrm{mg}=$ $3.0 \%(5 / 164)$, placebo/preladenant $5 \mathrm{mg}=0.6 \%$ $(1 / 175)$, and rasagiline $=2.3 \%(4 / 181)$. AST results were similar overall, but with a lower incidence of values $>3 \times$ ULN in both parts of the study. No Hy's Law cases were observed (a marker for clinical significance: ALT $3 \times$ ULN, alkaline phosphatase $>2 \times$ ULN, and associated with an increase in bilirubin $\geq 2 \times$ ULN). ${ }^{28}$

Post hoc efficacy analyses. Review of baseline participant characteristics did not reveal any notable differences between this and previous monotherapy trials (table e-3). There was a suggestion that baseline caffeine use was associated with $\mathrm{UPDRS}_{2+3}$ change from baseline score, with $>1 \mathrm{cup} / \mathrm{d}$ being associated with a significantly lower score than $\leq 1 \mathrm{cup} / \mathrm{d}, p=$ 0.035 . The association was not significant for $\geq 1$ cup/d vs $<1 \mathrm{cup} / \mathrm{d}, p=0.532$. Only a third of participants reported consuming $>1$ cup of caffeine per day (table 1). 
Table 2 Key efficacy results at week 26 (full analysis set)

\begin{tabular}{|c|c|c|c|c|c|}
\hline \multirow[b]{2}{*}{ Efficacy parameter } & \multicolumn{5}{|l|}{ Estimated response } \\
\hline & $\begin{array}{l}\text { Preladenant } \\
2 \mathrm{mg} \mathrm{BID}(\mathrm{n}=195)\end{array}$ & $\begin{array}{l}\text { Preladenant } \\
5 \mathrm{mg} \mathrm{BID}(\mathrm{n}=202)\end{array}$ & $\begin{array}{l}\text { Preladenant } \\
10 \mathrm{mg} \text { BID }(n=200)\end{array}$ & $\begin{array}{l}\text { Placebo } \\
\text { ( } n=195)\end{array}$ & $\begin{array}{l}\text { Rasagiline } \\
1 \mathrm{mg} \text { QD ( }=195)\end{array}$ \\
\hline \multicolumn{6}{|l|}{ Primary: UPDRS $_{2+3}$ score } \\
\hline Change from baseline & 0.30 & -1.00 & -1.80 & -2.20 & -1.90 \\
\hline Difference vs placebo $(95 \% \mathrm{Cl})$ & 2.60 (0.86 to 4.30$)$ & $1.30(-0.41$ to 2.94$)$ & $0.40(-1.29$ to 2.11$)$ & - & $0.30(-1.35$ to 2.03$)$ \\
\hline$p$ Value & 0.003 & 0.14 & 0.64 & - & 0.69 \\
\hline \multicolumn{6}{|c|}{$\begin{array}{l}\text { Secondary: Percent responders } \\
\text { ( } 220 \% \text { improvement in UPDRS } 2+3 \text { score) }\end{array}$} \\
\hline Change from baseline, $\%$ & 25.9 & 29.5 & 31.5 & 35.2 & 33.1 \\
\hline Difference vs placebo $(95 \% \mathrm{Cl})^{a}$ & $-9.7(-21.0$ to 1.82$)$ & $-6.3(-17.6$ to 5.05$)$ & $-3.7(-15.2$ to 7.99$)$ & - & $-2.3(-13.9$ to 9.24$)$ \\
\hline$p$ Value ${ }^{b}$ & 0.08 & 0.27 & 0.48 & - & 0.68 \\
\hline \multicolumn{6}{|l|}{ Secondary: UPDRS 2 score } \\
\hline Change from baseline & 0.30 & 0.10 & -0.20 & -0.40 & -0.20 \\
\hline Difference vs placebo $(95 \% \mathrm{Cl})$ & 0.70 (0.09 to 1.27$)$ & $0.50(-0.11$ to 1.04$)$ & $0.20(-0.42$ to 0.75$)$ & - & $0.10(-0.45$ to 0.70$)$ \\
\hline$p$ Value & 0.024 & 0.11 & 0.58 & - & 0.67 \\
\hline
\end{tabular}

Abbreviations: $\mathrm{Cl}=$ confidence interval; UPDRS = Unified Parkinson's Disease Rating Scale.

$\mathrm{N}$ represents the number of randomized and treated participants with at least 1 postbaseline value.

a Based on Miettinen and Numinen method using model-based adjusted effective sample size.

${ }^{\mathrm{b}} \mathrm{p}$ Value is for the estimated odds ratio based on a generalized linear mixed model with baseline average UPDRS $2+3$ as a covariate, treatment by time interaction as fixed effect, and participant as random effect.

Analyses of potential regional differences on $\mathrm{UPDRS}_{2+3}$ change from baseline score found that Latin America and Eastern Europe had the strongest placebo response whereas the rasagiline response was strongest in North America and the European Union (table 3). In a subgroup analysis by region, North

\section{Figure 2 Primary endpoint (change from baseline in Unified Parkinson's Disease Rating Scale (UPDRS) $2+3$ score over time)}

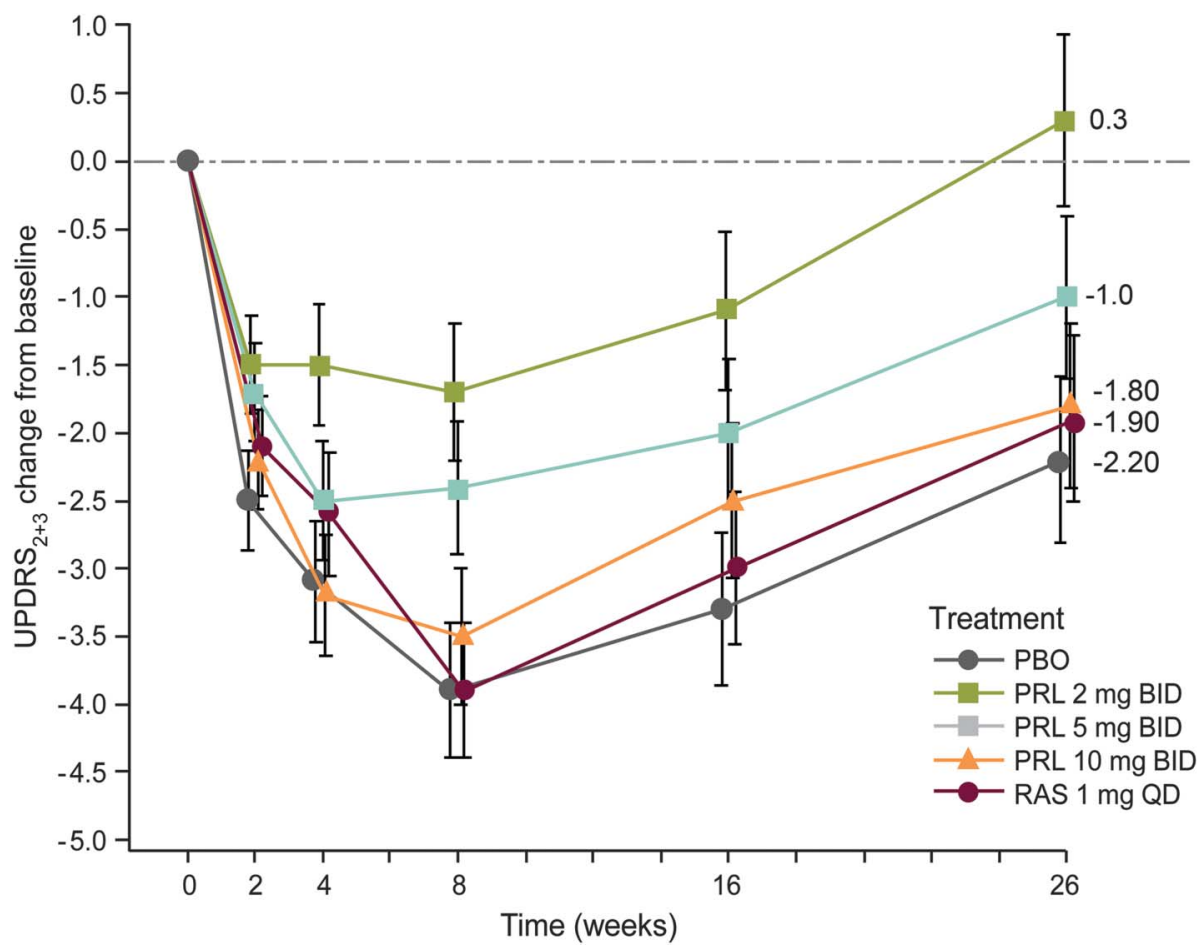

Estimated mean \pm SE by treatment group; full analysis set. $\mathrm{PBO}=$ placebo; $\mathrm{PRL}=$ preladenant; $\mathrm{RAS}=$ rasagiline. 
Table 3 Post hoc analysis: differences in UPDRS ${ }_{2+3}$ score at week 26 by region (full analysis set)

\begin{tabular}{|c|c|c|c|c|c|}
\hline Model estimate & $\begin{array}{l}\text { Eastern Europe } \\
(\mathrm{n}=284)\end{array}$ & $\begin{array}{l}\text { Latin America } \\
(n=228)\end{array}$ & $\begin{array}{l}\text { India and } \\
\text { Turkey }(n=73)\end{array}$ & $\begin{array}{l}\text { European } \\
\text { Union }(n=240)\end{array}$ & $\begin{array}{l}\text { North America } \\
(\mathrm{n}=162)\end{array}$ \\
\hline Baseline mean UPDRS $2+3$ score & 30.1 & 29.7 & 27.1 & 25.1 & 29.5 \\
\hline \multicolumn{6}{|l|}{ Change from baseline to week 26} \\
\hline Preladenant 2 mg BID & 0.9 & -0.8 & -1.9 & 0.6 & 1.8 \\
\hline Preladenant 5 mg BID & -0.8 & -3.8 & 0.0 & -0.1 & 0.7 \\
\hline Preladenant 10 mg BID & -1.9 & -3.5 & -3.0 & -0.7 & -1.8 \\
\hline Rasagiline $1 \mathrm{mg}$ QD & -0.2 & -4.2 & -2.5 & -2.3 & -0.8 \\
\hline Placebo & $-4.4^{a}$ & $-3.8^{a}$ & -2.1 & 0.1 & 0.7 \\
\hline \multicolumn{6}{|l|}{ Pairwise comparisons } \\
\hline Preladenant 2 mg BID vs placebo & 5.3 & 3.0 & 0.2 & 0.6 & 1.1 \\
\hline Preladenant $5 \mathrm{mg}$ BID vs placebo & 3.6 & 0.0 & 2.1 & -0.1 & 0.1 \\
\hline Preladenant $10 \mathrm{mg}$ BID vs placebo & 2.5 & 0.3 & -0.9 & -0.8 & -2.4 \\
\hline Rasagiline $1 \mathrm{mg}$ QD vs placebo & 4.2 & -0.3 & -0.4 & $-2.4^{b}$ & $-1.5^{\mathrm{b}}$ \\
\hline
\end{tabular}

Abbreviation: UPDRS = Unified Parkinson's Disease Rating Scale.

South Africa was excluded from the analysis due to the small number of randomized participants $(n=3)$.

a Strongest placebo response.

b Strongest rasagiline response.

America + European Union + India and Turkey showed results that were consistent with expectations of improvement for preladenant $10 \mathrm{mg}$ and rasagiline vs placebo (figure e-2A) whereas neither preladenant $10 \mathrm{mg}$ nor rasagiline differed from placebo in the Latin America + Eastern Europe subgroup (figure $\mathrm{e}-2 \mathrm{~B}$ ). Comparing across figures $\mathrm{e}-2 \mathrm{~A}$ and $\mathrm{e}-2 \mathrm{~B}$, it can be seen that the absolute values for preladenant $10 \mathrm{mg}$ and rasagiline were similar across the 2 regional subgroups while there was a striking difference in placebo response.

DISCUSSION The $\mathrm{A}_{2 \mathrm{a}}$ receptor antagonist preladenant when given as monotherapy in patients with early PD did not significantly improve UPDRS activities of daily living plus motor function scores compared to placebo. However, because the active control, rasagiline, also failed to demonstrate a significant improvement in UPDRS scores, it is not possible to determine whether these findings indicate inefficacy for preladenant or are related to issues of study conduct. The only other adequately sized monotherapy trial of a selective $A_{2 A}$ receptor antagonist to date also failed to demonstrate a significant effect of istradefylline. ${ }^{16}$

Despite these discouraging results, it would be premature to conclude that $\mathrm{A}_{2 \mathrm{a}}$ receptor antagonists do not have efficacy as monotherapy. It is possible that problems with the execution of clinical trials have hindered our ability to demonstrate efficacy. This is supported by the failure of rasagiline in our study. Rasagiline improved UPDRS in 2 previous large monotherapy trials (TEMPO and ADAGIO) ${ }^{26,29}$ and its clinical efficacy is supported by other studies and observations. ${ }^{17,18}$

There are a number of difficulties in conducting large trials in de novo parkinsonian patients. Structural error (inappropriate study design, entry criteria, endpoints) or operational error (errors in diagnosis, inappropriate investigators, inadequate training with inconsistent evaluations, and aberrant or missing data) can lead to failure of a study. The present study used a placebo-controlled, active-comparator design that was similar to previous de novo trials, and the entry criteria as well as endpoints were similar to other de novo trials. It is possible that the relatively high chance of receiving active treatment in our trial of $80 \%$, compared with, for example, $67 \%$ in the TEMPO trial $^{26}$ and $50 \%$ in the ADAGIO trial, ${ }^{29}$ may have contributed to the high placebo response.

Errors in diagnosis may occur in patients with early PD. Usually about $15 \%$ of participants enrolled in an early trial are eventually determined to have other diseases. The problem is further exacerbated in phase 3 trials, when more sites and participants are required than for smaller investigational trials, which can be performed at a few expert centers. However, this was also the case in studies with other treatments that found positive results. Moreover, we took steps to try to ensure accuracy of diagnosis (for example, a diagnosis based solely on bradykinesia and postural instability was considered insufficient) and special attention was paid to accurate diagnosis during the investigators meeting and with subsequent follow-up. Nevertheless, because of the large number of sites required for 
the trial, some less experienced investigators may have been selected, leading to an increase in wrong diagnosis and inaccurate evaluations.

Another potential issue relates to the measures used to assess outcomes (UPDRS in this case). Assessments should be performed in a standardized manner by experienced raters to minimize variability. For this trial, a comprehensive UPDRS rater training and qualification program was utilized so all reasonable steps were taken. Although the UPDRS in not very sensitive in mildly affected patients, particularly with regard to early motor deficits, it was able to detect treatment benefits vs placebo in previous de novo trials.

An interesting finding emerged in our post hoc analyses of regional differences. We identified a large placebo effect in Latin America and Eastern Europe with numerically greater improvement in UPDRS scores in these regions in the placebo than the preladenant or rasagiline groups. The reason for this finding is not known but a large placebo response was also observed in a phase 3 adjunct trial of preladenant in Latin America and Eastern Europe compared to North America and the European Union. ${ }^{13}$ Differences could potentially be due to clinical trials experience, cultural or language differences, genetic variation, or as yet unidentified reasons. In those regions in the present monotherapy trial where the placebo response was lowest (North America and the European Union), the rasagiline treatment difference vs placebo of -1.5 to -2.4 points was directionally in line with expectations, although still less than the -3.5 points the study was powered to detect and that has been proposed as a minimal clinically important change. ${ }^{30}$ Furthermore, in those regions with lowest placebo response, preladenant showed a dose response in efficacy, with the highest $10 \mathrm{mg}$ dose having similar efficacy to rasagiline (differences from placebo of -0.8 to -2.4 for preladenant $10 \mathrm{mg}$ ).

Another difficulty in interpreting the results from monotherapy trials is whether the appropriate doses were selected for evaluation. The doses of preladenant were chosen based on those used in the phase $2 b$ adjunct study in patients with moderate to severe PD on L-dopa, which demonstrated that 5 and 10 $\mathrm{mg}$ were effective. There was no prior experience of preladenant in patients with early PD who were not receiving dopaminergic therapy to guide dose selection. History with many dopaminergic agents suggests that treatment doses for early disease are similar to adjunct therapy in patients with moderate to severe PD. However, it is possible that this might not be true for $\mathrm{A}_{2 \mathrm{~A}}$ receptor antagonists.

Preladenant was generally well-tolerated in this trial, although the highest dose was associated with more AEs and discontinuations due to AEs than either placebo or rasagiline. Preladenant showed an increase in the percentage of patients with ALT increases but no Hy's Law cases, a marker for clinical significance, ${ }^{28}$ were observed. The increase in AEs and ALT with preladenant, particularly the highest $10 \mathrm{mg}$ dose, suggests that it was having biological activity despite the failure to demonstrate efficacy.

Our trial did not provide evidence that preladenant is effective as monotherapy in patients with early PD. The lack of efficacy on the primary endpoint of the active control, rasagiline, makes it difficult to interpret these results. Post hoc analyses suggest the possibility that some aspect of trial administration may have masked a potential drug effect. Definitive conclusions regarding the potential efficacy of preladenant specifically, and $A_{2 a}$ receptor antagonists as a class, as monotherapy in PD cannot be reached on the basis of this trial.

\section{AUTHOR CONTRIBUTIONS}

Prof. Stocchi, Dr. Hewitt, and Dr. Tzontcheva had full access to all the data in the study and take responsibility for the data, accuracy of the data analysis, and the conduct of the research. Prof. Stocchi was involved in study concept or design, acquisition of the data, interpretation of the data, drafted the manuscript, revised the manuscript for intellectual content, and approved the final version. Prof. Rascol was involved in study concept or design, acquisition of the data, interpretation of the data, revised the manuscript for intellectual content, and approved the final version. Prof. Hauser was involved in study concept or design, acquisition of the data, interpretation of the data, revised the manuscript for intellectual content, and approved the final version. Dr. Huyck was involved in study concept or design, acquisition of the data, analysis of the data, interpretation of the data, revised the manuscript for intellectual content, and approved the final version. Dr. Tzontcheva was involved in the analysis of the data, drafted the manuscript, interpretation of the data, revised the manuscript for intellectual content, and approved the final version. R. Capece was involved in acquisition of the data, interpretation of the data, and approved the final version. Dr. Ho was involved in study concept or design, acquisition of the data, interpretation of the data, revised the manuscript for intellectual content, and approved the final version. Dr. Sklar was involved in study concept or design, interpretation of the data, and approved the final version. Dr. Lines was involved in interpretation of the data, drafted the manuscript, revised the manuscript for intellectual content, and approved the final version. Dr. Michelson was involved in study concept or design, interpretation of the data, revised the manuscript for intellectual content, and approved the final version. Dr. Hewitt was involved in study concept or design, acquisition of the data, interpretation of the data, revised the manuscript for intellectual content, and approved the final version.

\section{ACKNOWLEDGMENT}

A scientific advisory committee composed of Merck and non-Merck investigators contributed to the development of the protocols, statistical analysis plans, analysis and interpretation of data; served as authors of the manuscript; and was responsible for the decision to submit the manuscript for publication. The authors thank Kenneth Wolski, MD, from Merck for contributions to the design and conduct of the studies and Sheila Erespe, MS, from Merck for editorial assistance.

\section{STUDY FUNDING}

The study was funded by Merck \& Co., Inc., Kenilworth, NJ. The funding organization was involved in the design and conduct of the studies; the collection, management, analysis, and interpretation of data; and preparation, review, and approval of the manuscript. 


\section{DISCLOSURE}

F. Stocchi was a member of the Scientific Advisory Committee for the studies and received honoraria from Merck for his services. His institution also received research grants from Merck for participation as investigator in the studies. Prof. Stocchi has also received research grants from Lundbeck and consulting payments from UCB, Britannia, Teva, and BIA. O. Rascol was a member of the Scientific Advisory Committee for the studies and received honoraria from Merck for his services. His institutions also received research grants from Merck for participation as investigator in the studies. Prof. Rascol has also received research grant from ANR, CHU Toulouse, France-Parkinson, INSERM-DHOS, Recherche Clinique Translationelle, MJ Fox Foundation, PHRC, Boehringer Ingleheim, Lundbeck, Teva, and UCB, and consulting payments from Abbvie, Britannia, Lundbeck, Ono, Bial, Mundipharma, Sanofi, Servier, Teva, UCB, Xenoport, Zambon, Neuroderm, Novartis, and Lilly. R. Hauser was a member of the Scientific Advisory Committee for the studies and received honoraria from Merck for his services. His institution also received research grants from Merck for participation as investigator in the studies. Dr. Hauser has also received consulting fees from Teva Pharmaceuticals, USB Biosciences, AbbVie, Novartis, Biotie Therapies, Lundbeck, Pfizer, Allergan Neuroscience, Neurocrine Biosciences, Chelsea Therapeutics, Auspex, Acadia Pharmaceuticals, Michael J. Fox Foundation, GLG, AstraZeneca, Acorda Therapeutics, Impax Pharmaceuticals, Cynapsus Therapeutics, USWorldMeds, Neuropore, and Prexton; salary support grants from National Parkinson Foundation; and salary from University of South Florida. S. Huyck is an employee of Merck Sharp \& Dohme Corp., a subsidiary of Merck \& Co., Inc., and owns stock/stock options in Merck. A. Tzontcheva is an employee of Merck Sharp \& Dohme Corp., a subsidiary of Merck \& Co., Inc., and owns stock/stock options in Merck. R. Capece is an employee of Merck Sharp \& Dohme Corp., a subsidiary of Merck \& Co., Inc., and owns stock/stock options in Merck. T. Ho is a former employee of Merck Sharp \& Dohme Corp., a subsidiary of Merck \& Co., Inc., and owns or owned stock/stock options in Merck. P. Sklar is an employee of Merck Sharp \& Dohme Corp., a subsidiary of Merck \& Co., Inc., and owns stock/stock options in Merck. C. Lines is an employee of Merck Sharp \& Dohme Corp., a subsidiary of Merck \& Co., Inc., and owns stock/stock options in Merck. D. Michelson is an employee of Merck Sharp \& Dohme Corp., a subsidiary of Merck \& Co., Inc., and owns stock/stock options in Merck. D. Hewitt is a former employee of Merck Sharp \& Dohme Corp., a subsidiary of Merck \& Co., Inc., and owns or owned stock/stock options in Merck. Go to Neurology.org for full disclosures.

Received September 29, 2016. Accepted in final form March 13, 2017.

\section{REFERENCES}

1. Armentero MT, Pinna A, Ferre S, Lanciego JL, Muller CE, Franco R. Past, present and future of $\mathrm{A}(2 \mathrm{~A})$ adenosine receptor antagonists in the therapy of Parkinson's disease. Pharmacol Ther 2011;132:280-299.

2. Kulisevsky J, Poyurovsky M. Adenosine A2A-receptor antagonism and pathophysiology of Parkinson's disease and drug-induced movement disorders. Eur Neurol 2012;67:4-11.

3. Jenner P, Mori A, Hauser R, Morelli M, Fredholm BB, Chen JF. Adenosine, adenosine A2A antagonists, and Parkinson's disease. Parkinsonism Relat Disord 2009; 15:406-413.

4. Hauser RA, Olanow CW, Kieburtz KD, et al. Tozadenant (SYN115) in patients with Parkinson's disease who have motor fluctuations on levodopa: a phase 2b, double-blind, randomised trial. Lancet Neurol 2014; 13:767-776.

5. LeWitt PA, Guttman M, Tetrud JW, et al. Adenosine A (2A) receptor antagonist istradefylline (KW-6002) reduces "off” time in Parkinson's disease: a double-blind, randomized, multicenter clinical trial (6002-US-005). Ann Neurol 2008;63:295-302.

6. Stacy M, Silver D, Mendis T, et al. A 12-week, placebocontrolled study (6002-US-006) of istradefylline in Parkinson disease. Neurology 2008;70:2233-2240.

7. Hauser RA, Shulman LM, Trugman JM, et al. Study of istradefylline in patients with Parkinson's disease on levodopa with motor fluctuations. Mov Disord 2008;23: 2177-2185.

8. Mizuno Y, Hasegawa K, Kondo T, Kuno S, Yamamoto M. Clinical efficacy of istradefylline (KW-6002) in Parkinson's disease: a randomized, controlled study. Mov Disord 2010; 25:1437-1443.

9. Pourcher E, Fernandez HH, Stacy M, Mori A, Ballerini R, Chaikin P. Istradefylline for Parkinson's disease patients experiencing motor fluctuations: results of the KW-6002-US-018 study. Parkinsonism Relat Disord 2012;18:178-184.

10. Hodgson RA, Bertorelli R, Varty GB, et al. Characterization of the potent and highly selective $\mathrm{A} 2 \mathrm{~A}$ receptor antagonists preladenant and SCH 412348 [7-[2-[4-2,4-difluorophenyl]1-piperazinyl] ethyl]-2-(2-furanyl)-7H-pyrazolo[4,3-e][1,2,4] triazolo[1,5-c]pyrimidin-5-amine] in rodent models of movement disorders and depression. J Pharmacol Exp Ther 2009;330:294-303.

11. Hodgson RA, Bedard PJ, Varty GB, et al. Preladenant, a selective $\mathrm{A}(2 \mathrm{~A})$ receptor antagonist, is active in primate models of movement disorders. Exp Neurol 2010;225: 384-390.

12. Hauser RA, Cantillon M, Pourcher E, et al. Preladenant in patients with Parkinson's disease and motor fluctuations: a phase 2, double-blind, randomised trial. Lancet Neurol 2011;10:221-229.

13. Hauser RA, Stocchi F, Rascol O, et al. Preladenant as an adjunctive therapy with levodopa in Parkinson disease: two randomized clinical trials and lessons learned. JAMA Neurol 2015;72:1491-1500.

14. Kalda A, Yu L, Oztas E, Chen JF. Novel neuroprotection by caffeine and adenosine $\mathrm{A}(2 \mathrm{~A})$ receptor antagonists in animal models of Parkinson's disease. J Neurol Sci 2006; 248:9-15.

15. Grondin R, Bédard PJ, Hadj Tahar A, Grégoire L, Mori A, Kase $H$. Antiparkinsonian effect of a new selective adenosine A2A receptor antagonist in MPTP-treated monkeys. Neurology 1999;52:1673-1677.

16. Mizuno Y, Kondo T. Adenosine A2A receptor antagonist istradefylline reduces daily OFF time in Parkinson's disease. Mov Disord 2013;28:1138-1141.

17. Stocchi F, Fossati C, Torti M. Rasagiline for the treatment of Parkinson's disease: an update. Expert Opin Pharmacother 2015;16:2231-2241.

18. Pistacchi M, Martinello F, Gioulis M, Zambito Marsala S. Rasagiline and rapid symptomatic motor effect in Parkinson's disease: review of literature. Neurol Ther 2013;3:41-66

19. The National Collaborating Centre for Chronic Conditions. Parkinson's Disease: National Clinical Guideline for Diagnosis and Management in Primary and Secondary Care. London: Royal College of Physicians; 2006.

20. Movement Disorder Society Task Force on Rating Scales for Parkinson's Disease. The Unified Parkinson's Disease Rating Scale (UPDRS): status and recommendations. Mov Disord 2003;18:738-750.

21. Nasreddine ZS, Phillips NA, Bédirian V, et al. The Montreal Cognitive Assessment, MoCA: a brief screening tool 
for mild cognitive impairment. J Am Geriatr Soc 2005;53: 695-699.

22. American Psychiatric Association. Diagnostic and Statistical Manual of Mental Disorders. Text Revision. 4th ed. Washington, DC: American Psychiatric Association; 2000.

23. Beck AT, Ward CH, Mendelson M, Mock J, Erbaugh J. An inventory for measuring depression. Arch Gen Psychiatry 1961;4:561-571.

24. Poewe W, Rascol O, Barone P, et al; Pramipexole ER Studies Group. Extended-release pramipexole in early Parkinson disease: a 33-week randomized controlled trial. Neurology 2011;77:759-766.

25. Watts RL, Jankovic J, Waters C, Rajput A, Boroojerdi B, Rao J. Randomized, blind, controlled trial of transdermal rotigotine in early Parkinson disease. Neurology 2007;68: 272-276.
26. Parkinson Study Group. A controlled trial of rasagiline in early Parkinson disease: the TEMPO Study. Arch Neurol 2002;59:1937-1943.

27. Rivera-Oliver M, Diaz-Rios M. Using caffeine and other adenosine receptor antagonists and agonists as therapeutic tools against neurodegenerative diseases: a review. Life Sci 2014;101:1-9.

28. Temple R. Hy's Law: predicting serious hepatotoxicity. Pharmacoepidemiol Drug Saf 2006;15:241-243.

29. Olanow CW, Rascol O, Hauser R, et al. A double-blind, delayed-start trial of rasagiline in Parkinson's disease. N Engl J Med 2009;361:1268-1278.

30. Hauser RA, Auinger P; Parkinson Study Group. Determination of minimal clinically important change in early and advanced Parkinson's disease. Mov Disord 2011;26: 813-818.

\section{Share Your Artistic Expressions in Neurology 'Visions'}

AAN members are urged to submit medically or scientifically related artistic images, such as photographs, photomicrographs, and paintings, to the "Visions" section of Neurology ${ }^{\circledR}$. These images are creative in nature, rather than the medically instructive images published in the NeuroImages section. The image or series of up to six images may be black and white or color and must fit into one published journal page. Accompanying description should be 100 words or less; the title should be a maximum of 96 characters including spaces and punctuation.

Learn more at www.aan.com/view/Visions, or upload a Visions submission at submit.neurology.org.

\section{Visit the Neurology ${ }^{\circledR}$ Resident \& Fellow Website}

Click on Residents \& Fellows tab at Neurology.org.

Now offering:

- Neurology ${ }^{\circledR}$ Resident \& Fellow Editorial team information

- "Search by subcategory" option

- E-pearl of the Week

- RSS Feeds

- Direct links to Continuum ${ }^{\circledR}$, Career Planning, and AAN Resident \& Fellow pages

- Recently published Resident \& Fellow articles

- Podcast descriptions

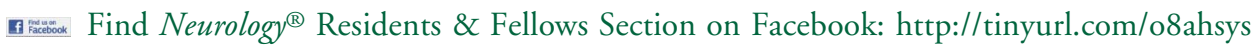

twitter Follow Neurology ${ }^{\circledR}$ on Twitter: http://twitter.com/GreenJournal 


\section{Neurology}

\section{Randomized trial of preladenant, given as monotherapy, in patients with early Parkinson disease}

Fabrizio Stocchi, Olivier Rascol, Robert A. Hauser, et al. Neurology 2017;88;2198-2206 Published Online before print May 10, 2017

DOI 10.1212/WNL.0000000000004003

\section{This information is current as of May 10, 2017}

\section{Updated Information \& Services}

Supplementary Material

\section{References}

Subspecialty Collections

Permissions \& Licensing

Reprints including high resolution figures, can be found at: http://www.neurology.org/content/88/23/2198.full.html

Supplementary material can be found at: http://www.neurology.org/content/suppl/2017/05/10/WNL.0000000000 004003.DC1

http://www.neurology.org/content/supp1/2017/05/10/WNL.0000000000 004003.DC2

This article cites 28 articles, 5 of which you can access for free at: http://www.neurology.org/content/88/23/2198.full.html\#\#ref-list-1

This article, along with others on similar topics, appears in the following collection(s):

Class I

http://www.neurology.org//cgi/collection/class_1

Clinical trials Randomized controlled (CONSORT agreement) http://www.neurology.org//cgi/collection/clinical_trials_randomized_c ontrolled_consort_agreement

Parkinson's disease/Parkinsonism http://www.neurology.org//cgi/collection/parkinsons_disease_parkinso nism

Information about reproducing this article in parts (figures,tables) or in its entirety can be found online at:

http://www.neurology.org/misc/about.xhtml\#permissions

Information about ordering reprints can be found online: http://www.neurology.org/misc/addir.xhtml\#reprintsus

Neurology ${ }^{\circledR}$ is the official journal of the American Academy of Neurology. Published continuously since 1951, it is now a weekly with 48 issues per year. Copyright () 2017 American Academy of Neurology. All rights reserved. Print ISSN: 0028-3878. Online ISSN: 1526-632X.

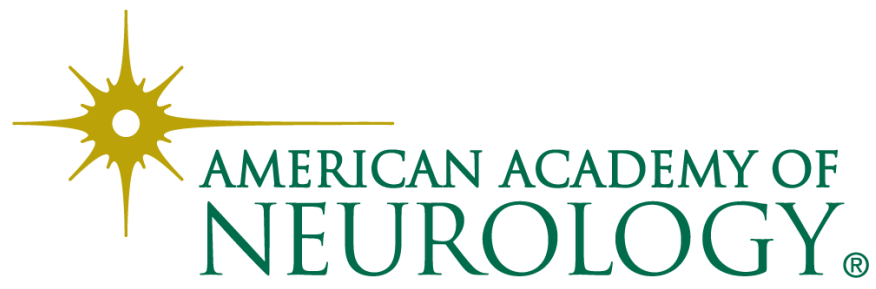

